\title{
A cincuenta y tres pasos del autor: Genios y Creativos
}

\author{
Héctor Esquivias-Zavala
}

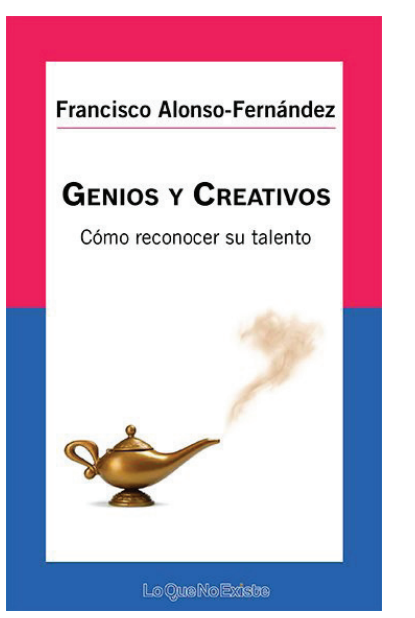

doi:

10.17711/SM.0185-3325.2018.012
Recibir el encargo de escribir la reseña del libro número cincuenta y tres de la autoría del Profesor Francisco Alonso-Fernández es un honor. Conocí al autor en 2012, en un foro donde se dirigió a un grupo de psiquiatras en formación y desde ese día me impresionó su cultura inconmensurable y la calidez de su persona. Quienes le conocen coincidirán en que este querido y admirado maestro de psiquiatras es un referente intelectual. Es Catedrático Emérito de Psiquiatría y Psicología Médica de la Universidad Complutense de Madrid y Presidente Honorífico de la Asociación Europea de Psiquiatría Social y del Instituto de Psiquiatras de Lengua Española.

Genios y Creativos, publicado por la editorial Lo que no existe, en febrero de 2017, es un ensayo científico-humanista, un nuevo y pequeño tratado del genio en el que el autor busca contribuir a hacer justicia a un grupo incomprendido: los hombres genio y, a través de la reflexión intelectual y afectiva, reconocerles una justa calificación social.

El autor explora en el primer capítulo las diferencias entre el genio, el sabio y el superdotado. Los sabios se caracterizan por su riqueza en conocimientos, los superdotados por su riqueza de inteligencia fluida y los genios por su inteligencia cristalizada y gran capacidad creativa.

Alonso-Fernández describe estas modalidades de inteligencia, puntualizando las diferencias entre ellas y cómo se desarrollan a lo largo de la vida desde el contexto personal y social de los sujetos que analiza. Para el autor, el superdotado navega a favor de la corriente, por lo que pertenecen a este grupo los triunfadores académicos. En cambio, los genios van completamente a contracorriente, aportando novedades ya sea mediante la invención, el descubrimiento o la creación. Así, la rebelión de Lutero es la razón de la Ilustración contra la autoridad, la rebelión de Marx contra el capitalismo, la rebelión del León Tolstoi contra la historia y la civilización y la de Nietzsche contra la razón y la moral; para el autor de Genios y Creativos, en todos estos casos subyace la pasión por la libertad.

Por lo anterior, la obra del genio es generalmente mal recibida y su reconocimiento social sucede en la mayoría de los casos post mortem, tal fue el caso de El Greco, Goya o Tiziano. Alonso-Fernández cita al Señor Verde, personaje de la obra de Pessoa: "el poeta nació después de su muerte, porque fue después de su muerte cuando nació la estimación por el poeta". De acuerdo con esto, cabría preguntarnos ¿Acaso en el suicidio, reportado con mayor frecuencia en los poetas que en otros literatos observamos la auto-develación del artista como acto final de su obra?

Alonso-Fernández retoma el problema XXX planteado por Aristóteles (trad. 2004) en el mundo clásico sobre el vínculo entre los hombres excepcionales y la melancolía (Northwood, 1998) y demuestra la vigencia del aforismo de Séneca "No existe ningún gran genio sin un toque de demencia". Lo anterior, nos conduce a reconocer la honestidad del poeta alemán Rilke, cuando escribió: "Las obras de arte son el resultado de haber estado en peligro, del hecho de haber ido hasta el extremo de una experiencia que ningún hombre puede sobrepasar". Alonso-Fernández ahonda en el análisis caracterológico de poetas y filósofos vinculando a éstos con sus obras y diferenciando entre los últimos al genio filosófico (situado, 
según él, en la interfaz entre el literato y el científico), del filósofo ensayista, más cercano a los escritores narrativos.

En los primeros capítulos destaca los factores condicionantes del desarrollo intelectual a la luz del estado del conocimiento actual como la epigenética y otras condiciones biológicas y coloca a la par de éstos ciertos rasgos de la personalidad y otros elementos afectivos vinculados al aprendizaje como el interés, la curiosidad y el amor a la cultura que contribuyen al despliegue de la inteligencia. Por medio de los modelos de la inteligencia de Horn (1970) el autor observa que la creatividad no tiene edad y lo ejemplifica con artistas que alcanzaron el reconocimiento en etapas avanzadas de su vida como Miguel Ángel, Leonardo o Tiziano. En este punto el lector comienza a asirse a la idea de que un autor nonagenario puede también ser un genio.

En los siguientes seis capítulos, a manera de los salones de una galería, el autor nos conduce a un análisis taxonómico de los distintos elementos que conforman la genialidad de los pintores, los escritores y los músicos, precisa en ellos los rasgos de independencia, la firmeza, el inconformismo, la rebeldía avivada, el sentido del humor y la voluntad de trabajo. Como sujetos de este análisis desfilan Picasso, Hemingway, Kafka, Dostoievski, Beethoven, entre otros.

Alonso-Fernández es un erudito del estudio psicohistórico de varios personajes como lo demuestran sus obras: $E l$ enigma Goya (Alonso-Fernández, 1999), Historia personal de los Austrias Españoles (Alonso-Fernández, 2000), Historia personal de la monja Teresa de Jesús (Alonso-Fernández, 2013). El autor realiza en Genios y Creativos, tal vez su más abundante análisis de esta disciplina, facilitando su comprensión y captando las conexiones que dan sentido al genio con su obra. Analiza la influencia del entorno y la circunstancia del genio desde los aspectos históricos, sociales, políticos y psicopatológicos. Sin embargo, para Alonso Fernández, ninguno de éstos, de forma exclusiva, determina la presencia o ausencia de la genialidad. El autor realiza además un análisis a la luz dela teoría psicoanalítica y señala a la constelación matriarcal, el padre imperceptible y la madre amantísima como la base para el desarrollo del impulso creador y observa este fenómeno en el caso del genio Leonardo da Vinci, producto del complejo de Edipo según Freud, pero con la variante de no haber sido relacionado con su madre sino con su madrastra quien fue idealizada por éste, de esta manera la prevalencia del universo femenino sobre el padre hostil y distante ofrecen la base para el desarrollo del impulso creador y, en este caso, también de la homosexualidad. El complejo de Edipo se manifiesta de manera más evidente entre los genios, especialmente entre los escritores. En el caso de Dostoievsky, Alonso-Fernández cuestiona y difiere de la interpretación psicoanalítica que considera que el autor de Los hermanos Karamazov expresó en esta obra los inconscientes deseos parricidas y, en cambio, coincide más con el escritor francés André Gide (1952), cuando concluye que en la obra de Dostoievsky, éste no se pintó a sí mismo, sino lo que habría podido ser de no haber llegado a ser él mismo. Al respecto, podemos observar en ambas interpretaciones la función catalizadora del proceso creativo.

El autor, poseedor también de un peculiar talento y docto en el tema, analiza minuciosamente el vínculo entre la enfermedad mental y la creatividad, vínculo revelado en textos que son un referente para la psicopatología de la expresión, como Genio y Locura, de Cesare Lombroso (1872) o Marcados con fuego, de Kay Redfield Jamison (1998). El autor contribuye a esta pléyade de autores con la peculiar mirada del psiquiatra experimentado y precisa los elementos psicopatológicos de los principales trastornos mentales como el trastorno bipolar y la depresión estacional y el impacto favorecedor de los ritmos creativos en la obra de pintores, músicos y poetas, en quienes, explica, se puede atribuir este efecto a que el proceso creativo se encuentra más anclado en el inconsciente a diferencia de otras áreas como la arquitectura o la ciencia. Sobre el trastorno depresivo, identifica la anergia y el aislamiento como los síntomas que obstaculizan la creatividad. Derivado de este análisis nos aproxima a responder al cuestionamiento ¿La creatividad ocurre gracias o pese a ella? Cualquier respuesta nos conducirá a reconocer la contribución del artista, pero sobretodo a comprender lo que sufrieron para lograrlo.

Finalmente, dedica un apartado a la homosexualidad y al fenómeno del suicidio. Sobre el primer punto, diferencia los rasgos de la personalidad de André Gide y Marcel Proust, escritores de principios del siglo XX (al cual también pertenecen "los Contemporáneos" mexicanos) y cómo asumieron su preferencia sexual a través de su obra. Pero, si esto obedeció a un contexto histórico y social con el fin de encajar en el constructo social de la época como lo plantea el autor, cabe preguntarnos ¿Qué devenir en la expresión artística se manifiesta en los artistas de este colectivo actualmente? ¿Qué deseos pretenden cumplir en lo simbólico a través de su obra?

De forma magistral Alonso-Fernández cierra el último capítulo con un análisis del fenómeno suicida, para ello establece un debate dialéctico con el escritor rumano Ciorán que es el mayor apologista teórico sobre la libertad de elegir el suicidio evidenciando el contrasentido en la vida de éste cuando expresó "Yo no he podido jamás matarme". El autor narra el trágico final de Larra, Kleist, Koestler y Nerval y analiza sus tendencias autodestructivas. De esta manera, los genios no eximidos de su condición humana, son víctimas de un razonamiento erróneo, $y$ en el acto suicida parecen olvidar lo que a través de las vicisitudes y del sufrimiento han contribuido a la belleza.

Guiados por la narrativa exquisita del autor y de su talento para comprender los sentimientos y la conducta humana, la lectura de este libro los conducirá a la reflexión, al autodescubrimiento del propio talento y al justo reconocimiento de los genios en la historia de la humanidad. 


\section{REFERENCIAS}

Alonso-Fernández, F. (1999). El enigma Goya. Madrid: Fondo de Cultura Económica.

Alonso-Fernández, F. (2000). Historia personal de los Austrias españoles. México: Fondo de Cultura Económica.

Alonso-Fernández, F. (2013). Historia Personal de la Monja Teresa de Jesús. Madrid: La hoja del monte.

Aristóteles. (trad. 2004). Problemas. Madrid: Gredos.
Jamison, K. R. (1998). Marcados con fuego: La enfermedad maniaco-depresiva y el temperamento artístico. México: Fondo de Cultura Económica.

Lombroso, C. (1872). Genio e follia. Milan: Gaetano Brigola.

Gide, A. (1952). Dostoievsky. Londres: Ardent Media.

Horn, J. L. (1970). Organization of data on life-span development of human abilities. In Life-span developmental psychology: Research and theory. Nueva York: Academic Press.

Northwood, H. (1998). The melancholic mean: the Aristotelian Problema XXX.1. Asheville, CN: Paideia. 